\title{
MINISSÉRIE OU TELENOVELA
}

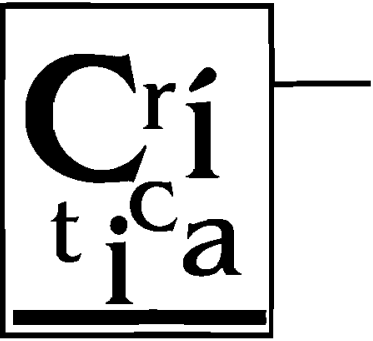

\section{A minissérie é obra fechada, de autor e não sofre interferências das oscilações da audiência como ocorre com a telenovela}

Em meados de 1996, eis que a Rede Globo de Televisão joga mais lenha na fogueira, ao veicular, em pleno horário nobre, uma mininovela em 35 capítulos: O Fim do Mundo, texto de autoria de Dias Gomes, com a colaboração de Ferreira Gullar.

Ora, sabendo-se como se sabe que a discussão sobre a natureza e as características dos gêneros na teleficção brasileira (telenovela, minissérie, seriado e unitário, basicamente) é um assunto dos mais interessantes e polêmicos para quem trabalha sobre a matéria, cabe-nos perguntar: é uma telenovela esta mininovela? É uma minissérie este novo média-metragem, que a Rede Globo resolve veicular no horário nobre, por razões de ordem prática?

Consultando entrevista de Dias Gomes sobre o assunto ${ }^{1}$, encontramos, em uma das perguntas dirigidas ao autor, que:

Folha: A mudança no horário da exibição de $\mathrm{O}$ Fim do Mundo, que iria ao ar às $22 \mathrm{~h} 30 \mathrm{~min}$, obrigou-o a alterar o material já produzido?

A resposta é negativa e não modifica os fatos. O que importa é que, segundo a reportagem, O Fim do Mundo estava previsto para ir ao ar às $22 \mathrm{~h} 30 \mathrm{~min}$, portanto no horário tradicionalmente reservado às minisséries. Circunstâncias posteriores, de qualquer tipo, levaram a emissora a colo- cá-la no horário tradicional das $20 \mathrm{~h} 30 \mathrm{~min}$, horário de telenovela.

Deixando de lado, por agora, as razões pelas quais a emissora resolveu modificar seus planos e seu comportamento habitual, talvez caiba, de modo mais pertinente, tentar de novo identificar e distinguir a minissérie e a telenovela.

Inicialmente, é forçoso pensar em termos de extensão; a telenovela tem sido, de maneira flagrante, e pelo menos no Brasil dos últimos vinte anos, uma produção teleficcional alongada, de mais de cem e menos de duzentos capítulos, situando-se, ultimamente, na faixa de 180 . Isto significa que seu texto acaba redundando em cinco mil e quinhentas a perto de seis mil páginas escritas e a sua duração total - duração na tela fica por volta de 150 horas.

Estes números são bastante impressionantes, e fazem pensar em quanto de trabalho - bom ou mau - se necessita para realizar uma telenovela e em como é difícil encontrar material (bom ou mau!) para preencher esses espaços.

\section{A AUTORA \\ Renata Pallottini \\ Professora Doutora do Departamento de Artes Ce- nicas da ECA-USP, autora de poesia, teatro e prosa.}

1. ABREU, Gilberto de. "Mininovela é produto de luxo". Folha de São Paulo, Caderno TvFolha, 07/04/96. p.5. 


\section{ESTRUTURA DRAMATÚRGICA}

Uma das características da telenovela, portanto, e em conseqüência do já exposto, se traduz em termos dramatúrgicos: é preciso criar histórias, ficção, enredo para preencher as páginas e os minutos de culebrón ${ }^{2}$ ameaçador. É preciso enredar, ligar, relacionar os fios desta história, instituindo, por conseqüência, muitas outras.

É preciso que a história básica, a coluna dorsal, $o$ tronco central da árvore que a telenovela constitui, seja forte e tenha seiva suficiente para agüentar as tramas secundárias, os galhos emergentes, as ramas que conduzem os conflitos paralelos.

Esses conflitos paralelos são, em geral, muitos, por volta de 20,30 subtramas, conduzidas por personagens que devem ser criados, caracterizados e expostos de maneira a ficar patente que agem, que têm vontade, que têm função, que existem dramaticamente, em suma. Tudo isso deve ser unificado pela história central, a qual necessitará força, vitalidade, energia, para que desperte interesse, crie suspense e justifique a atenção que um público eventual, um grande público, de preferência, possa lhe dar.

Ora, torna-se evidente pelas próprias dimensões de ambas que a minissérie exige menos conteúdo ficcional, basta-se com histórias mais simples e mais curtas, com menor número de personagens, de sets $^{3} \mathrm{e}$ de complicações. Em comparação ao grande romance de folhetim que seria a telenovela, a minissérie é um romance curto, uma símile da novela literária, se podemos utilizar essa comparação.
O Fim do Mundo conta a história de Joãozinho de Dagmar e de suas visões fatalistas. O personagem é uma espécie de Cassandra ${ }^{4}$ masculina, vidente respeitado em Tabacópolis -, cidadezinha da Bahia que vive da cultura do fumo - paranormal que eventualmente cura e prevê o futuro. Lidando, de forma um pouco ligeira, com os conceitos de realismo mágico, os autores propõem que, a partir daí, "se o mundo vai acabar, que acabe satisfazendo as nossas vontades".

Vê-se que o projeto foi ambicioso, voltado à linha inaugurada na televisão pelo mesmo Dias Gomes (que longe estão os dias de Stela Calderón! ${ }^{5}$ ), inovador intemerato, que lançou na telinha, com as saramandaias e os roques, as notas do nosso real maravilhoso, do nosso realismo mágico, quer se opte por seguir as linhas de Alejo Carpentier, quer aquelas expostas por Garcia Marquez.

"A vida cotidiana na América Latina demonstra que a realidade está cheia de coisas extraordinárias..."

... diz Garcia Marquez em recente livrodepoimento. Sem dúvida, Dias Gomes (e Aguinaldo Silva) pensam da mesma maneira, e o resultado é a atraente série de obras de ficção televisivas onde se foge de maneira explícita ao receituário comum de amores desencontrados, mães, pais e filhos perdidos, ascensão social e prêmios/castigos.

Mas aqui, pela primeira vez, se não nos falha a memória, o esquema é utilizado em programa de média duração. Quando carros são tragados pelo asfalto, terremotos abrem fendas no chão, chuvąs destroem plantações e raios explodem nos céus, em sequiência às

\footnotetext{
2. Maneira como os hispano-americanos chamam a novela. Significa cobra grande.

3. Sets, local das gravaçōes ou filmagens.

4. Personagem da tragédia grega: Édipo Rei, de Ésquilo, Cassandra é a profetisa das desgraças.

5. Pseudônimo de Dias Gomes no início de sua carreira.
} 
predições de Joãozinho de Dagmar, está-se fazendo a colocação de acontecimentos inauditos, que vão provocar consequiências graves e surpreendentes, mas não, de maneira alguma, de molde a durar na tela seis ou sete meses. $O$ que tiver de acontecer acontecerá e será visto em 35 dias, ou seja, em um mês e meio aproximadamente.

Porém, e mais importante: o texto da mininovela está, já, escrito e pronto para ser gravado. Diz o autor, aliás, que já está envolvido em outro projeto, este também de mini... série? Novela?

"A mininovela é vista pela Globo como um produto de luxo, que dá prestígio. Pode ser que queiram implantar esse novo formato. Afinal, já me encomendaram outra produção".

Portanto, o autor de O Fim do Mundo já está fazendo outro trabalho.

E, por conseqüência, esta obra não tem e não pretende ter uma das características fundamentais da telenovela padrão brasileira: a de ser uma obra em aberto, escrita enquanto vai ao ar, sujeita a sofrer todas as modificações que a circunstância, os acontecimentos do dia, o sucesso e o insucesso, o êxito de audiência e outros detalhes mais podem the impor.

\section{O COTIDIANO REgULA A TRAMA}

As últimas produções do ramo, da Globo como de outras emissoras, têm sido marcadas pelas mencionadas circunstâncias. Estes modificadores da ficção, estes influxos que invadem a história ficcional, em sua porosidade, podem ser de vários tipos. Tentemos arrolá-los:

1. sucesso ou insucesso de público, afetando ator ou atores, histórias, tramas, famílias ou sets;

2. acontecimentos marcantes ou circunstanciais da vida real - advento de festas nacionais e populares - Natal, Carnaval -, de eventos políticos, mortes, catástrofes etc.;

3. incidentes que afetam os participantes da leitura da telenovela em suas vidas particulares: enfermidades, mortes, afastamentos, litígios trabalhistas etc.;

4. fatos sociais que solicitam o autor de maneira imperiosa: as desigualdades, as greves, os problemas que afetam os pobres, os negros, as crianças, as minorias em geral, e que se agudizam no decurso da criação de um trabalho.

Ora, todos esses acontecimentos e outros mais que sempre se poderão arrolar, fazem da telenovela padrão um programa vivo, atual, reconhecível em sua urgência $\mathrm{e}$, posteriormente, em sua historicidade. Certas telenovelas que se poderia supor excessivamente datadas, ou excessivamente locais, podem ser, hoje em dia, revistas e estudadas como testemunhas de um tempo e de um lugar que, a um determinado momento, se documentou.

Essa característica é talvez a que realmente distingue a nossa telenovela atual; não faz a telenovela, necessariamente, melhor que a minissérie, mas lhe confere um caráter e, quiçá, um papel social que a minissérie, por mais produto de luxo que seja, não tem, embora seu texto, sua proposta e sua execução sejam mais elaborados formalmente - o que de fato são. 
Resumo: A recente veiculação pela Rede Globo, em horário nobre, da minissérie em 35 capítulos 0 Fim do Mundo, de Dias Gomes e Ferreira Gular, leva a autora a discutir as diferenças entre a estrutura dramatúrgica da telenovela e da minissérie; a influência dos índices de audiência sobre a telenovela e suas caracteristicas particulares enquanto produto cultural nacional.

Palavras-chave: telenovela, minissérie, Rede Globo, $O$ Fim do Mundo, teledramaturgia.
Abstract: The recent transmission by Globo station of the serial in 35 chapters 0 fim do mundo (The end of the world) written by Dias Gomes and Ferreira Gular leads to the discussion of the differences between the dramatic composition of a telenovela and a serial and also the influence of the audience rates on the telenovela and its specific characteristics as a national cultural product.

Key-words: telenovela, serial, Rede Globo (Globo Station), O Fim do Mundo (The End of the World), TV drama. 